\title{
Crítica à teoria do trabalho imaterial a partir da crítica à divisão dos três paradigmas produtivos
}

\section{Criticism of the theory of immaterial labor from the standpoint of the division of the three productive paradigms}

DOI: $10.46814 /$ lajdv3n3-009

Recebimento dos originais: 01/05/2021

Aceitação para publicação: 30/06/2021

\section{Vinícius Oliveira Santos}

Doutor em Sociologia pela Universidade Estadual de Campinas (UNICAMP). Professor Substituto de Sociologia da UFCat, Catalão, Goiás, Brasil. Endereço institucional: Av: Dr. Lamartine Pinto de Avelar, 1120. Setor Universitário. Catalão/GO. CEP: 75704-020 Autor do livro Trabalho Imaterial e

Teoria do Valor em Marx: semelhanças ocultas e nexos necessários

Universidade Federal de Catalão

\section{RESUMO}

A produção teórica principal do que aqui chamamos de recente teoria do trabalho imaterial, difundida principalmente por Antonio Negri, Maurizio Lazzarato, Michael Hardt, tem como um de seus fundamentos a apreensão da dinâmica produtiva de acordo com a sucessão dos paradigmas econômicos. A transição de um paradigma a outro seria determinado pelo crescente número de trabalhadores agregados no setor primário (agricultura e extração), secundário (fabril) ou terciário (serviços). Daí decorre a compreensão do trabalho imaterial (situado, segundo esses autores, no setor terciário) enquanto uma forma de atividade laborativa que rompe com os elementos do trabalho material, típicos do setor secundário. Não haveria, segundo este modelo teórico, correlações necessárias entre as formas materiais e imateriais de trabalho. $\mathrm{O}$ artigo em tela almeja empreender, a partir da crítica à visão dos três setores, uma crítica à compreensão que desarticula o trabalho material do trabalho imaterial usando como peça fundamental as teorizações de Karl Marx e de alguns autores marxistas que apontam para uma visão imbricada entre tais formas de trabalho.

Palavras Chave: Sociologia do Trabalho, Trabalho Imaterial, Setor de Serviços.

\section{INTRODUÇÃO}

Os elementos aqui expostos constituem parte de uma pesquisa teórica desenvolvida entre 20082010 sob a orientação do Prof. Edilson José Graciolli, atrelada ao Grupo de Pesquisa Trabalhadores, Sindicalismo e Política. O texto em tela consiste em uma versão alterada do artigo apresentado no Seminário do Trabalho (UNESP - 2010). Para maiores aprofundamentos à temática, sugerimos a leitura de nossas pesquisas posteriores (Santos, 2013; Santos 2018). Tais estudos não foram aqui inseridos tendo em vista a preservação do conteúdo original do artigo mediante o convite à publicação por parte da Latin American Journal of Development. Reiteramos que várias questões aqui mencionadas superficialmente foram trabalhadas pormenorizadamente em momentos posteriores. $\mathrm{Da}$ 
mesma forma, em outros textos tomamos como pressupostos elementos que foram aqui desenvolvidos com maiores detalhes.

As conceituações da recente teoria do trabalho imaterial ${ }^{l}$ orbitam ao redor de autores italianos que designaram a si mesmos como neomarxistas, mas que promovem profundas críticas às principais categorias de Marx. Maurizio Lazzarato (2001d), em um artigo intitulado Trabalho autônomo, produção por meio de linguagem e 'General Intellect', atribui à corrente operaísta italiana a elaboração do conceito de trabalho imaterial, ampliada, posteriormente, por seus continuadores dos quais o próprio Lazzarato faz parte. O operaísmo italiano pode ser considerado uma escola de pensamento cuja produção teórica foi ligada ao neomarxismo italiano no final da década de 1950 e início de 1970, tendo Antonio Negri como um de seus principais articulistas (Cocco, 2001).

Nos interstícios de tal vertente teórica, a maior parte das obras voltadas à analise do trabalho imaterial foi escrita tendo em vista "o debate francês sobre reestruturação produtiva, crise do fordismo e transformações do trabalho" (COCCO, 2001, p. 7). Em suma, as profundas transformações ocorridas principalmente na década de 1970 formaram o substrato empírico através do qual a recente teoria do trabalho imaterial foi se desenvolveu. É importante notar que os autores tomaram como campo empírico a chamada Terceira Itália (região que agrega Milão, Turim, Bolonha, Florença, Veneza, Gênova etc.) onde existem vários grupos de pequenas empresas que adotam a inovação contínua e o uso de métodos "flexíveis" de produção.

O que podemos verificar com essas teorizações, é um processo de repulsa à teoria marxiana e marxista tendo como principal justificativa a redução dos postos de trabalho industriais no limiar da reestruturação produtiva dos anos 70 . Este processo teve como uma das muitas consequiências a diminuição de empregos formais no setor fabril e expansão de outras formas de trabalho, entre elas "um aumento das atividades dotadas de maior dimensão intelectual” (ANTUNES, 2005, p. 63). Na presença destes fenômenos nasceu a recente teoria do trabalho imaterial, marcada por diversas rupturas com a base teórica marxiana, buscando fornecer um novo material teórico para explicar o que seria um novo tipo de trabalho: o trabalho que não produz uma mercadoria palpável, material, mas tem como resultado um serviço, uma informação etc..

Do ponto de vista da originalidade do debate no contexto em questão, os representantes principais da recente teoria do trabalho imaterial são Antonio Negri, Maurizio Lazzarato, Michael

\footnotetext{
${ }^{1}$ Recente aqui em dois sentidos: cronologicamente, por ser posterior às formulações da Economia Política, campo teórico que já utilizava este conceito (fato que passa despercebido nos estudos contemporâneos); e recente por não conceber a existência de formas importantes de trabalho imaterial em momentos anteriores ao processo do que Negri e Hardt chamam de pós-modernização econômica, como veremos.
} 
Hardt, André Gorz ${ }^{2}$ e, no meio acadêmico brasileiro, Giuseppe Cocco. Nos seus apontamentos, a teoria marxiana foi declarada defasada em muitos de seus elementos fulcrais (como por exemplo, a teoria do valor), pois o trabalho nos termos marxistas estaria sendo substituído por "um novo regime de produção" comandado pelo trabalho imaterial. (HARDT; NEGRI, 2002, p. 225).

Neste artigo analisaremos criticamente um dos pilares da recente teoria do trabalho imaterial: o pressuposto da divisão entre três setores da economia (agricultura, indústria e serviços) e as implicações decorrentes na compreensão do capitalismo atual enquanto um modelo oriundo do processo de pós-modernização econômica, na qual domina o trabalho imaterial. Por isso, torna-se necessário uma apreciação acerca dos sentidos da reestruturação produtiva que indicará a visão fragmentária dos três setores produtivos. Tentaremos desvendar as conseqüências teóricas oriundas nesse tipo de análise.

\section{O PROCESSO DE PÓS-MODERNIZAÇÃO ECONÔMICA E OS SENTIDOS DA REESTRUTURAÇÃO PRODUTIVA SEGUNDO A RECENTE TEORIA DO TRABALHO IMATERIAL.}

Nesta primeira seção do artigo abordaremos as questões concernentes à visão fragmentada dos três setores da economia (agricultura, fábrica e serviços) nos autores da recente teoria do trabalho imaterial, dos quais Antonio Negri, Mauricio Lazzarato, Michael Hardt e Giuseppe Cocco são os principais expoentes para o que nos propusemos analisar. Explicitaremos o movimento através da qual as formas de produção dominantes tornaram-se preponderantemente imateriais e situadas no setor terciário da economia segundo a matriz teórica em questão. O presente item perpassa, sistematicamente, pelos sentidos da reestruturação uma vez que nesta apreciação tornar-se-á evidente a visão dicotômica entre as diferentes fases do capitalismo nos autores que nos incumbimos verificar. Estes elementos, conforme veremos, possuem alguns limites que serão criticados neste trabalho, em momento oportuno.

No polêmico livro Império, Hardt e Negri (2002) afirmam que domina na configuração econômica atual o ciclo de pós-modernização econômica. Este processo resultaria na abertura de novo paradigma econômico marcado pela preponderância dos serviços e da manipulação da informação, o chamado setor terciário, na economia: "um sintoma dessa mudança está patente nas alterações quantitativas no emprego." (HARDT; NEGRI, 2002, p. 306, destaques nossos). Os autores preconizam que a concentração do contingente de trabalhadores em torno do trabalho na agricultura (setor

\footnotetext{
${ }^{2}$ Andre Gorz possui um posicionamento teórico extremamente distinto dos outros autores mencionados. No entanto, tendo em vista o tema que estamos desenvolvendo (concepção etapista dos paradigmas produtivos e negação da teoria do valor marxiana) há importantes similaridades.
} 
primário), ou do trabalho industrial - que para eles é corresponde a trabalho fabril - (setor secundário), ou do trabalho como serviço (setor terciário), revelaria a entrada no respectivo paradigma. A transição do setor primário para o secundário é nomeado por eles como o processo de modernização da economia, e, a do secundário para o terciário, recebe o título de pós-modernização produtiva. A inserção neste novo paradigma foi resultado de um processo de reestruturação produtiva, a saber: a passagem do fordismo ao pós-fordismo (ou sociedade pós-industrial) e inaugura a produção do trabalho imaterial. Como percebemos, na visão dos autores, há uma nítida fragmentação dos paradigmas produtivos a partir da qual a entrada na era da dominância do setor terciário na economia teve como movimento balizador a reestruturação produtiva nos idos de 1970. Por estas razões, nossa proposta de análise deve partir da análise da visão que privilegia a divisão da economia em três setores, mas sem se contentar com ela. A apreciação que faremos deve indicar quais mecanismos incidiram influência fulcral na transição do setor secundário para o setor terciário. Segundo os autores analisados nesse item do artigo, estes mecanismos são os mesmos que implodiram a reestruturação produtiva que mencionamos acima. É necessário, portanto, que vejamos mais de perto como se deu, segundo essa vertente teórica, o processo de reestruturação produtiva que implantou o modelo pós-fordista a partir década de 1970, que marcaria o início fenomênico do chamado capitalismo cognitivo e a suposta preponderância do setor terciário na produção.

De acordo com as idéias de Giuseppe Cocco (2001), na década em questão, duas grandes tendências profundas eram observáveis, isto é, havia um duplo processo que estava diretamente relacionado à mudança de paradigma produtivo (do secundário ao terciário) na década em questão. De um lado, o investimento maciço em tecnologias de automação que promoveu processos de "externalização e descentralizações produtivas". (COCCO, 2001, p. 19). A segunda grande tendência percebida naquela década foi o processo que Negri (1991) chama de "autonomia operária" marcado pela nova estrutura de classe cujos contornos não diziam respeito às formas de dualização classificatória (marxistas, diga-se de passagem) dos operários fordistas, mas sim, aos trabalhadores do “novo regime de acumulação", isto é, o "operário social” em vez do "operário massa" do taylorismo (COCCO, 2001, p. 20).

Desses dois movimentos, em primeiro lugar analisaremos a tendência que diz respeito às características técnicas e organizacionais da reestruturação. Feito isso, pormenorizaremos a questão da autonomia operária, que está relacionada, seguindo a classificação de Negri, Lazzarato, Hardt e Cocco, a uma nova subjetividade. É o que explicitaremos a partir de agora.

Negri e Hardt (2004) já haviam formulado, de forma breve, questão da descentralização típica da era da produção imaterial pós-fordista: “a fábrica não pode mais ser concebida como o lugar paradigmático da concentração do trabalho e da produção; processos de trabalho se moveram para fora 
das paredes da fábrica para investirem toda a sociedade." (HARDT; NEGRI, 2004, p. 9). No entanto, esses autores não aprofundam com quais meios técnicos tornou-se possível a descentralização. O autor que sistematiza com mais clareza o caráter técnico da reestruturação produtiva que marcou o processo de um paradigma pós-fordista sob a base teórica dos autores da recente teoria do trabalho imaterial é Giuseppe Cocco.

A inserção de novas tecnologias de informação e comunicação (NTIC) na visão de Cocco teve importância central na transformação do regime de acumulação baseado na grande indústria e na emergência de novas formas produtivas que "era na verdade um deslocamento da própria função produtiva para as atividades imateriais" (COCCO; SILVA; GALVÃO, 2003, p. 7).

Segundo Antonella Corsani (2003) as NTIC por serem tecnologias cognitivas e relacionais permitem a valorização sobre as qualidades de conhecimento do trabalhador. Neste contexto, o conhecimento e a inovação manifestam-se enquanto força produtiva central da produção: em vez da produção de mercadorias por meio de mercadorias, a era pós-fordista, que é simultaneamente pósindustrial, compreende a produção de conhecimentos por meio de conhecimentos. Essa valorização do conhecimento peculiar ao "novo modo de produção" não altera sua natureza geral mesmo quando atrelada à produção de mercadorias materiais.

Por não ser possível quantificar materialmente o resultado desse tipo de trabalho, e aqui já se distanciando de Marx, é um lugar-comum da vertente teórica analisada nesse item afirmar que o novo paradigma produtivo, onde domina o trabalho imaterial, rompeu com as antigas formas de trabalho assalariado. Este é um dos pressupostos centrais do que os autores chamam de capitalismo cognitivo. Percebamos que a passagem do fordismo ao pós-fordismo é considerada em termos de uma ruptura com a forma anterior de acumulação. Sobre esse assunto Corsani afirma: "desincorporados de qualquer suporte material, os conhecimentos desequilibram as teorias do valor, tanto a marxista quanto a neoclássica" (CORSANI, 2003, p. 28). A teoria do valor teria uma base material e quantitativa e, por tal motivo, estaria superada no capitalismo cognitivo.

Prosseguindo com a teorização de Giuseppe Cocco, Gerardo Silva e Alexander Galvão, os autores também explicitam que "a inovação não depende tão-somente dos aspectos tecnológicos" (COCCO; SILVA; GALVÃO, 2003, p. 13), mas evolvem aspectos organizacionais do ciclo da produção. Na nova forma de produção social, isto é, produção comandada pelo trabalho imaterial, haveria um processo de interação redes-redes. Neste modelo organizacional e institucional, empresas e instituições trocariam informações, conhecimentos e aprendizados entre si de modo que as inovações necessárias às atividades produtivas são alteradas incessantemente.

Nos elementos levantados em Cocco, a reestruturação produtiva da década de 1970 foi tratada no aspecto da mudança tecnológica e organizacional. Indicamos a dupla tendência que explicitamos 
no início da exposição do presente item nos falta considerar pressupostos que subsidiem o caráter político da reestruturação e que reflita sobre as influências e pressões ensejados pela a organização da classe trabalhadora, cuja luta culminou na alteração da estrutura produtiva.

Em termos, esta lacuna pode ser preenchida a partir das teorizações conjuntas de Hardt e Negri (2002 e 2004). De fato, os autores conseguem extrair a partir de Marx o motor das grandes mudanças nos paradigmas produtivos na ordem do capital: colocar rédeas na tendência à queda na taxa de lucro, maximização da extração de mais-valia, e a tentativa de ampliar a dominação sobre a classe trabalhadora. Sobre o último aspecto, que diz respeito ao movimento político das bruscas alterações no âmbito produtivo, dizem os autores:

Lutas proletárias constituem - em termos reais, ontológicos - o motor do desenvolvimento capitalista. Elas obrigam o capital a adotar níveis de tecnologia cada vez mais altos, e dessa maneira transformam os processos de trabalho. As lutas forçam o capital continuamente a reformar as relações de produção e transformar as relações de dominação. (HARDT; NEGRI, 2002, p. 228).

Mediante o quadro de lutas operárias que marcou a década de 1960 e 1970, Hardt e Negri demonstram que dois caminhos se abriram para o capital. O primeiro deles, "que tinha limitada eficácia” (HARDT; NEGRI, 2002, p. 288) foi a opressão repressiva. Essa estratégia conservadora buscava restabelecer o controle do capital sobre a força de trabalho reconstruindo um sistema hierárquico através do uso repressivo da tecnologia. Entretanto, as transformações tecnológicas inseridas neste contexto não permitiam que o mesmo controle rígido do taylorismo/fordismo fosse exercido. Imediatamente um segundo caminho foi aberto: o caminho da opção reativa. Neste caminho, é na capacidade criativa dos trabalhadores da época que reside a transformação que o capital será forçado a adotar no futuro. O poder dessa capacidade criativa, nas palavras dos autores, "dita os termos e a natureza da transformação" e "inventa, efetivamente, as formas sociais e produtivas" (HARDT; NEGRI, 2002, p. 289). Essa é a chave principal para entendermos a reestruturação produtiva e o pósfordismo nos autores analisados.

Em outros termos, esse segundo caminho indica que o capital teve que enfrentar a "nova produção de subjetividade do proletariado" (HARDT; NEGRI, 2002, p. 290) concedendo um sistema produtivo concebido previamente pelos próprios operários que vão além das formas de dominação e exploração anteriores.

O início dessa transição se deu ainda no que eles chamam de "regime disciplinar", onde começaram as lutas contra o sistema fordista cuja limitação e rigidez "já não conseguia conter as necessidades e os desejos dos jovens” (HARDT; NEGRI, 2002, p. 294) que se concentraram num processo de recusa ao "programa fixo de produção". 
Em outra obra (Hardt; Negri, 2004, p. 274-275), os mesmos teóricos pormenorizam essa recusa do trabalho, que marca a passagem para a nova fase de relações sociais, passível de ser constatada por alguns fatores tais como, em primeiro lugar, a recusa individual do trabalho nos moldes fordistas; e, em segundo lugar, uma recusa em massa da relação entre trabalho abstrato da fábrica taylorista. ${ }^{3}$

A recusa ao trabalho em questão criou "novas formas de mobilidade e flexibilidade, novos estilos de vida" (HARDT; NEGRI, 2002, p. 295). Esse momento de contestação foi a ocasião em que foram concebidas as formas e demonstradas as necessidades que apontavam a possibilidade de um novo paradigma produtivo. ${ }^{4}$ Segundo os autores, a mudança que promoveu a passagem do fordismo ao pós-fordismo:

foi antecipada pelo surgimento de uma nova subjetividade [...] foi impulsionada, de baixo para cima, por um proletariado cuja composição já tinha mudado. O capital não precisou inventar um novo paradigma porque o momento realmente criativo já tinha ocorrido. (HARDT; NEGRI, 2002, p. 296).

Fica claro que segundo a concepção de Antonio Negri e Michael Hardt, o sentido da alteração do paradigma produtivo que abriu às portas ao pós-fordismo não é inferido mediante a necessidade imanente de o capital alterar sua composição orgânica, elevando o capital constante à custa do capital variável, com vistas à intensificação do controle do potencial de reivindicação dos trabalhadores como queriam os autores marxistas. Ao contrário, segundo os autores, a transição para o que alguns chamam de automação flexível teve como fulcro a prévia concepção desse sistema produtivo por parte dos trabalhadores somada às lutas para implantá-lo, almejando uma maior capacidade de escolha no processo de trabalho.

Os trabalhadores "usaram a era disciplinar, e acima de tudo seus momentos de dissidência e suas fases de desestabilização política [...] para ampliar os poderes sociais do trabalho e redesenhar o conjunto das necessidades e desejos aos quais os salários e o bem-estar social tiveram de responder." (HARDT; NEGRI, 2002, p. 293). Conseqüentemente, foram fornecidas respostas criativas incumbidas de "organizar um novo modo de produção" (HARDT; NEGRI, 2004, p. 274) (Isto é, um modo de produção distinto do modo de produção capitalista). Este novo modo é caracterizado por três respostas: 1) pela automação na fábrica, 2) pelas relações sociais produtivas computadorizadas, e 3) pelo regime de consumo controlado pelo fluxo monetário privilegiando as corporações. Porém, os autores afirmam que tais respostas não obtiveram êxito enquanto dominação propriamente capitalista, uma vez que o

\footnotetext{
${ }^{3}$ Essa recusa se "proliferou em milhões de práticas diárias: Era o estudante universitário que experimentava o LSD, em vez de procurar emprego; era a jovem que não queria casar e constituir família” etc. (HARDT, NEGRI 2002, p. 295).

4 “Os movimentos anteviram a consciência capitalista de uma necessidade de mudança paradigmática na produção, e ditaram sua forma e sua natureza.” (Ibdem)
} 
resultado desse complexo de interações intensificou a desproporção entre a reestruturação e a da nova subjetividade da classe trabalhadora. ${ }^{5}$

A nova subjetividade, resultado do capitalismo, mas a ele avesso, seria, na perspectiva de Negri e Hardt, o elemento que, por meio da "recusa do trabalho", estimulou a última grande reestruturação produtiva. Por mais estranha que pareça a questão proposta por autores que se denominam neomarxistas, a subjetividade operária que disseminou a "recusa do trabalho" fez com que tais trabalhadores fugissem das fábricas negando a rigidez hierárquica fordista. $\mathrm{O}$ esvaziamento do processo produtivo incidiu de maneira forçosa sobre os patrões obrigando-os a adotar novas tecnologias e métodos de trabalho para que fosse possível empregar a produção com menos força de trabalho, acatando, sem resistência as atitudes da nova subjetividade. É justamente essa a acepção de Lazzarato: isso ocorreu '“[...] comme si l' 'impératif économique' les avait obligés à se plier aux conditions d'autonomie et de coopération de la composition de classe."6 (LAZZARATO, 1992, s/p). Os capitalistas, aqui, teriam se curvado mediante a reivindicação operária da "recusa do trabalho". Logo, na teoria do grupo de autores em questão, "a inovação tem sua gênese no desenvolvimento dos indivíduos.” (LESSA, 2005, p. 46).

As teses da "recusa do trabalho" preconizam que esta postura de embate diante o capitalismo da era fordista inaugurou um "novo modo de produção" (NEGRI, 1991, p. XXV apud LESSA) distinto do modo de produção capitalista. É uma luta da classe trabalhadora contra os imperativos que a obrigavam a trabalhar.

Tendo em vista esses elementos, quais seriam as diferenças essenciais entre o fordismo e o pósfordismo de acordo com o pensamento de Negri, Lazzarato, Hardt e Cocco? Tentaremos responder a questão nos parágrafos que se seguem.

No capitalismo industrial, que, segundo eles existiu desde a época de Marx até o esgotamento do modelo fordista, o espaço da produção de mercadorias era rígido e delimitado pelo o chão-defábrica. Aqui, a hierarquia reinava absoluta. Como ainda não havia iniciado o processo de descentralização que indicamos anteriormente, a existência da fábrica estava separada da sociedade. $\mathrm{O}$ capitalista nesse período dominava a produção com mãos de ferro. Ao contrário, o que se observa na era da pós-modernização econômica onde reina a produção imaterial é que a estrita delimitação fordista não pôde ser aplicada pelo fato de que nas configurações do sistema de trabalho atual a produção não se encontra restrita à fábrica e, forçado pelas circunstâncias o capitalista teve que conceder um processo

\footnotetext{
${ }^{5}$ Amorim preconiza que as formulações da teoria do trabalho imaterial estão relacionadas à "forma como compreendem a formação da classe à qual pertencem.” (AMORIM, 2009, p. 147).

6 “'[...] como se o 'imperativo econômico' tivesse os obrigado a dobrar-se ante as condições de autonomia e cooperação da composição de classe” Tradução nossa.
} 
de produção diferente, ditado pela "liberté qu'il est obligé de ré-introduire" 7 (LAZZARATO, 1992, $\mathrm{s} / \mathrm{p})$.

A empresa e a economia típicas do sistema pós-industrial "são fundadas sobre o tratamento da informação" cujo centro não seria a produção de mercadorias, mas sim, "a comercialização e a financeirização" (LAZZARATO, 2001a, p. 44). Agora, há a preocupação central com a produção e o consumo da informação. A empresa pós-industrial, ao contrário da fordista:

[...] mobiliza importantes estratégias de comunicação e de marketing para reaprender a informação (conhecer a tendência do mercado) e fazê-la circular (construir um mercado). [...] Parece então que a mercadoria pós-industrial é o resultado de um processo de criação que envolve tanto o produtor quanto o consumidor. (LAZZARATO, 2001a, p. 44)

A reestruturação da década de 1970, que procedeu a referida pressão operária, não promoveu nenhuma mudança na organização da produção ${ }^{8}$, uma vez que de acordo com Hardt e Negri (2002) o momento criativo do que veio a ser tal reorganização produtiva já tinha ocorrido. A essência da pósmodernização econômica seria, portanto, operária e não capitalista.

Na mesma linha de pensamento, Maurizio Lazzarato nega que a passagem do fordismo ao pósfordismo esteja vinculada ao processo de valorização do capital conforme as suposições marxistas:

Le passage d'une forme de coopération à une autre n'est pas lié tellement aux changements technologiques et aux lois d'évolution du mode de production capitaliste, mais plutôt à la modification de la subjectivité collective ouvrière qui a lieu par la lutte et l'organisation. $\left(\right.$ LAZZARATO, 1992, s/p) ${ }^{9}$

Percebemos então uma ruptura de caráter incisivo na qual Lazzarato, Negri, Hardt e Cocco em relação a Marx, que tinha a compreensão de que "todos os meios para desenvolver a produção redundam em meios de dominar e explorar o produtor" (MARX, 2008a, p. 749) caracterizando um avanço do capital sobre o trabalho.

Do ponto de vista da vertente teórica que estamos nos ocupando, o desemprego constatado no limiar da transição para o pós-fordismo não foi conseqüência dessa reestruturação, mas sim, foi,

\footnotetext{
7 "Liberdade que foi obrigado a reintroduzir". Tradução nossa.

8 “Esta transformação começou a manifestar-se de maneira evidente no curso da década de 1970, isto é, na primeira fase da reestruturação, quando as lutas operárias e sociais, opondo-se à retomada da iniciativa capitalista, consolidaram os espaços de autonomia conquistados [...] A subordinação desses espaços de autonomia e organização do trabalho imaterial às grandes indústrias ("processo de recentralização") no curso da fase de reestruturação sucessiva (emergência do modo de produção pós-fordista) não muda, mas reconhece e valoriza a nova qualidade do trabalho." (NEGRI; LAZZARATO, 2001, p. 27)

9 “A passagem de uma forma de cooperação à outra não é vinculada tanto às mudanças tecnológicas e às leis de evolução do modo de produção capitalista, mas antes na modificação da subjetividade coletiva operária que teve lugar na luta e na organização." Tradução nossa.
} 
somado à luta dos trabalhadores para um espaço de trabalho mais livre, a causa dela. Os operários se recusaram a submeter-se às antiquadas formas de trabalho e tinham "a perspectiva de entrar no regime regulado pela fábrica social”. (HARDT; NEGRI, 2002, p. 294). As teses dos marxistas que viam nesse fenômeno um processo de ação do capital para retomar os patamares de lucro estariam completamente equivocadas.

O tipo de trabalho que pode ser aí inserido é, sobretudo, o trabalho imaterial, uma vez que a estrutura produtiva não está mais pautada pela rigidez e quantificação do que é produzido no âmbito da empresa contemporânea (até porque, segundo a teoria que estamos analisando, o conteúdo informacional do trabalho imaterial não é passível de quantificação). O surgimento do trabalho imaterial na produção ${ }^{10}$ aparece como emanação direta do processo de pós-modernização econômica, embora a concepção organizacional desse tenha sido fruto de um "momento criativo" anterior à própria reestruturação, por parte dos trabalhadores. A análise dessa forma de trabalho, segundo Cocco (2001, p. 8), fornece uma contribuição para a compreensão do novo regime de acumulação instaurado. Fundamentalmente, no item que se segue, serão expostas as características essenciais do trabalho imaterial.

\section{OS PONTOS DE CRÍTICA EM RELAÇÃO À RECENTE TEORIA DO TRABALHO IMATERIAL}

Desde a sua Contribuição à crítica da economia política, um livro freqüentemente relegado pelos leitores, Karl Marx já havia apontado um elemento que embasa o que aqui vamos expor. Segundo ele "o resultado a que chegamos não é que a produção, a distribuição, a troca, o consumo, são idênticos, mas que todos eles são membros de uma totalidade, diferenças em uma unidade." (MARX, 2008, p. 255, destaques nossos). A correlação necessária entre os vários momentos do complexo mercantil capitalista mencionada por Marx indica uma visão distinta dos teóricos da recente teoria do trabalho imaterial e, ao mesmo tempo, fornece base para a crítica que faremos aqui. Em outro momento fica mais explicita seu não alinhamento na visão da divisão dos três setores (agricultura e extração, indústria e serviços), que pode ser provado pelo seu conceito de "industrial”: "industrial aqui no sentido de abranger todo ramo de produção explorado segundo o modo capitalista" (MARX, 2008b, p. 62, destaques nossos). Portanto, quando Marx fala em indústria, ele está mencionando algum ramo apoderado pela produção capitalista. O sentido de indústria nos moldes marxianos é utilizado de uma forma mais ampla do que a visão corrente atualmente, que concede ao termo indústria o mesmo significado de fábrica.

\footnotetext{
${ }^{10}$ Por esfera produtiva os autores compreendem a atividade industrial que seria sinônima a atividade fabril.
} 
Podemos ilustrar o exposto citando o que Marx, no livro segundo de $O$ Capital, chama de indústria dos transportes: "O que a indústria de transportes vende é a própria mudança de lugar. $\mathrm{O}$ efeito útil produzido está inseparavelmente ligado ao processo de transporte, isto é, ao processo de produção da indústria de transporte.” (MARX, 2008b, p. 255). A indústria de transportes não produz um bem intercambiável no mercado comum de mercadorias. Ela vende, por assim dizer, um serviço, um resultado imaterial. A demonstração de que Marx ao citar processos de trabalho onde o resultado não é um objeto palpável não adota como critério definidor o fato deste trabalho estar inserido no setor de serviços, em vez disso, define esse trabalho, no caso da indústria de transportes, encontrando-se inserido em um "processo de produção", impulsionado pelo capital-industrial, ou seja, onde impera as leis de produção do capital: a força de trabalho, ao consumir-se com os demais elementos da produção, cria valor novo, a mais-valia, um valor excedente, a ser apropriado pelo capital. O processo de trabalho aí inscrito tem como finalidade a valorização do capital: "produzir mais-valia é a lei absoluta desse modo de produção" (MARX, 2008a, p. 721). Logo, não podemos concordar com as teses de Negri e Lazzarato (2001) que afirmam a não possibilidade do trabalho imaterial não se reproduzir na exploração da mais-valia.

É proveitoso que nesta altura da explanação teórica seja inserida outra categoria marxiana indispensável ao que estamos analisando aqui: a definição de trabalho produtivo e trabalho improdutivo. A indústria de transportes, no sentido que descrevemos acima, produz mais-valia e, por este motivo, o trabalho que circunscreve este ramo é o trabalho produtivo. Há, todavia, setores que agregam trabalhadores assalariados sem que haja a criação da mais-valia. Vejamos a questão mais de perto.

trabalho produz, para usar a terminologia marxiana, um efeito útil, isto é, uma utilidade, um valor-de-uso. Em contrapartida, segundo Marx (2004) nem todo efeito útil, mesmo quando desdobrado no seio da sociedade capitalista, carrega em si uma mais-valia. O trabalho despendido neste processo é, portanto, trabalho improdutivo. O critério para demarcação entre o trabalho produtivo e o trabalho improdutivo fica claro nesta passagem:

Como o fim imediato e (o) produto por excelência da produção capitalista é a mais-valia, temos que somente é produtivo aquele trabalho que ( [sic] e só é trabalhador produtivo aquele possuidor da capacidade de trabalho que diretamente produza mais-valia; por isso, só aquele trabalho que seja consumido diretamente no processo de produção com vista à valorização do capital. (MARX, 2004, p. 108, destaques do autor).

Mas se estamos tratando do trabalho sob a ordem do capital, o "agente real do processo de trabalho" (MARX, 2004 p. 110) não é o trabalhador individual, mas sim a cooperação de diversas capacidades de trabalho. Desta maneira, amplia-se a gama de capacidades de trabalho que se 
enquadram no conceito de trabalho produtivo: "um trabalha mais com as mãos, outro mais com a cabeça, este como diretor, engenheiro, técnico etc., aquele como capataz, aqueloutro como operário manual ou até como simples servente" (MARX, 2004, p. 110) ambos são submetidos ao processo de valorização do capital, de produção e extração da mais-valia.

O trabalho improdutivo, por sua vez, é a modalidade de trabalho que "é consumido por causa do seu valor de uso e não como trabalho que gera valores de troca; é consumido improdutivamente" (MARX, 2004, p. 111, destaques do autor), em outros termos, não gera valor novo, não valoriza o capital, não produz mais-valia, não se converte em parte do capital variável. Ele é consumido como serviço, como utilidade. Daqui podemos afirmar: o trabalho que não gera valor é improdutivo do ponto de vista do capital, porém, é extremamente útil à sua reprodução. Os trabalhos envolvidos na mera mudança de forma do valor (que diz respeito à venda de mercadorias no comércio) são, sob esta delimitação, trabalhos improdutivos. Sendo assim, por mais que Marx afirme a tendência do capital diminuir o tempo de circulação, não se trata de diminuir a importância da circulação ou do trabalhador improdutivo, pois os trabalhadores da compra e venda "realizam função necessária, pois o processo de reprodução também abrange funções improdutivas. Trabalha como qualquer outra pessoa, mas o conteúdo de seu trabalho não cria valor nem produto”. (MARX, 2008b, p. 149).

Hardt, Negri e Lazzarato incorrem no equivoco de considerar todo trabalho imaterial como serviço e como não produtor de mais-valia e, deste modo, "independente da atividade empreendedora capitalista" (LAZZARATO; NEGRI, 2001, p. 31). Para análise do modo capitalista de produção este critério é infundado. Em primeiro lugar, pela razão evidente de que há trabalhos imateriais que geram valor e mais-valia, como por exemplo, o trabalho envolvido na indústria de transportes. Em segundo lugar, mesmo os trabalhos imateriais improdutivos não se encontram independentes e livres da atividade capitalista. Um exemplo seriam as atividades comerciais que, ao se tornarem complexas sob o processo de produção e reprodução capitalista, modificam-se em atividades capitalistas, com trabalhadores assalariados cujas jornadas de trabalho também são divididas em tempo de trabalho excedente e tempo de trabalho necessário. Além do que já levantamos, a apuração dos conceitos de trabalho produtivo e trabalho improdutivo são úteis para a desmistificação do caráter do trabalho vendido sob a forma de serviços: o modo pelo qual Negri, Lazzarato e Hardt apresentam o trabalho no "setor terciário" faz com que a relação social de exploração na qual o modo capitalista de produção é erguido apresente-se transfigurada.

Em contraposição a essa vertente, podemos fazer referência à contribuição de Jean Lojkine (2002) que percebe a interpenetração de atividades industriais e atividades informacionais de modo que "não há expansão de serviços sem desenvolvimento correlativo da indústria" (LOJKINE, 2002, p. 255), inclusive, para citar um exemplo, o autor aponta que na República Federal da Alemanha, no 
período entre 1981 e 1986, houve um aumento da criação de empregos relacionados à siderurgia, que, por se tratar de uma atividade fabril, não seria imaterial na designação dos operaístas.

Sobre a relação mútua entre a atividade fabril e os chamados serviços, nos EUA ocorreu um fenômeno de enfraquecimento de ambas:

O desaparecimento de inteiros segmentos da indústria americana, notadamente em ramos de forte valor agregado e altos salários, acarretou a atrofia de atividades de serviços subsidiárias da indústria manufatureira (empresas de projetos e engenharia, estabelecimentos financeiros, companhia de seguros, transportes, reparação e manutenção etc.). (LOJKINE, 2002, p. 257).

Por isso, de acordo com a teoria de Lojkine, a oposição mecanicista entre a produção de empregos no setor terciário e o declínio do setor secundário, um dos pilares da recente teoria do trabalho imaterial, constituiria um fracasso tendo em vista a divisão internacional dos países capitalistas industrializados que permite a transposição da atividade industrial para países com níveis salariais mais baixos. Logo, a reestruturação produtiva da década de 1970 não pode ser posta, pelas razões expostas, em termos de mudança setorial, como colocam Hardt e Negri. E mais: a tese segundo a qual o trabalho imaterial teria rompido com as "antigas" formas de trabalho mostra-se infundada de acordo com as inferências de Lojkine.

A apuração destes elementos somados à contribuição de Marx (2008b) que trata um trabalho conhecido como serviço inserido "em um processo de produção" é útil para a desmistificação do caráter do trabalho vendido sob essa forma: não há autonomia dos chamados serviços em relação ao processo de produção. A forma que Negri, Lazzarato e Hardt apresentam o trabalho no "setor terciário" faz com que a relação social de exploração na qual o modo capitalista de produção é erguido apresente-se transfigurada. Sendo assim, as determinações essenciais deste fenômeno, que na visão marxista estão ligadas ao processo de valorização do capital, tornam-se camufladas.

Neste caminho, Eleutério Prado (2005) indica uma concepção fetichista da teoria de Negri, Hardt e Lazzarato. De acordo com ele, estes autores atribuem o caráter da produtividade do trabalho (trabalho relacionado à produção de mais-valia) como estando relacionado a resultados materiais. Por atentarem-se simplesmente ao resultado do trabalho imaterial eles não apresentaram as relações sociais fundamentais que são inerentes ao processo do trabalho imaterial. Segundo Prado, "pouco importa aqui se o valor gerado está cristalizado em produtos materiais ou imateriais ou em produtos que têm existência separada ou não do ato de trabalhar" (PRADO, 2005, p. 54), pois a condição para que o trabalho seja produtivo ao capital é, simplesmente, o fato de estar ligado à produção de valor.

O mesmo autor ainda critica Negri, Hardt, Lazzarato e Cocco por se basearem no conceito de "regime disciplinar" (que, como já vimos, diz respeito à rigidez do modelo fordista). Prado afirma que 
a atenção a esta questão fez como que os processos de gênese e superação desse modelo produtivo não fossem delineados na teoria.

Em relação ao trabalho intelectual, as passagens que expressam a "independência progressiva da força de trabalho intelectual e trabalho imaterial em face do domínio capitalista" (LAZZARATO; NEGRI, 2001, p. 31) são comuns. Desconsideram o modo pelo qual o capital absorve o trabalho intelectual:

Fisiologicamente, cabeça e mãos são partes de um sistema; do mesmo modo, o processo de trabalho conjuga o trabalho do cérebro e o das mãos. Mais tarde, se separam e acabam por se tornar hostilmente contrários. O produto deixa de ser o resultado imediato da atividade do produtor individual para tornar-se produto social, comum, de um trabalhador coletivo, isto é, de uma combinação de trabalhadores, podendo ser direta ou indireta a participação de cada um deles na manipulação do objeto sobre incide o trabalho. [...] Para trabalhar produtivamente não é mais necessário executar uma tarefa de manipulação do objeto de trabalho; basta ser órgão do trabalhador coletivo, exercendo qualquer uma das funções fracionárias. (MARX, 2008a, p. 577).

Não há a necessidade de manipulação de um objeto material para que tal trabalho seja considerado produtivo, ou que seja absorvido pelo capital. Na acepção de Marx, portanto, no processo de produção capitalista não há independência objetiva do trabalho intelectual ali inserido. Por mais que ele esteja separado dos trabalhadores manuais, ele pode, conjuntamente com o "órgão do trabalhador coletivo" exercer funções produtivas. A imbricação entre o trabalho que manipula a matéria (trabalho material) e o trabalho que demanda maior intelectualidade (trabalho imaterial) já está posta desde Marx.

As teses da "recusa ao trabalho" nas quais expressam uma pretensa situação onde os trabalhadores esvaziaram as fábricas fordistas, de acordo com Lessa, "invertem causa e efeito tomando a reestruturação produtiva como consequiência - e não causa - do fechamento de postos de trabalho." (LESSA, 2005, p. 52). Logo, segundo os autores da recente teoria do trabalho imaterial, não foi a intensa necessidade de valorização do capital frente a crise e a concorrência que expulsaram os trabalhadores de seus postos de trabalho. No julgamento de Lessa "eles não perguntam à história o que ocorreu; antes, proclamam 'à história: deves ter ocorrido de tal ou qual modo"” (LESSA, 2005, p. 52).

Lessa ainda critica o conteúdo idealista da teoria de Negri, Lazzarato e Hardt: estes autores teriam atribuído que as idéias (no caso, a idéia de recusa ao trabalho) determinaram o movimento do real imputando o trabalho imaterial. Essa forma de trabalho teria sido algo previamente estabelecido na consciência dos trabalhadores. E é aqui que Lessa afirma que as suposições desses autores seriam um "construto puramente axiológico" (LESSA, 2005, p. 53). Podemos inferir que esse marxista brasileiro não vê nenhum ponto de tangência entre a realidade concreta e a construção teórica dos autores da recente teoria do trabalho imaterial: “'trabalho imaterial' é uma contradição em termos no universo marxiano" (LESSA, 2005, p.72), pois, para ele, o trabalho é sempre material. 
Além desse fator as teses operaístas do trabalho imaterial foram alvo de críticas por parte de Lessa por cancelar a contradição entre capital/trabalho e afirmar a identidade entre o "empreendedor político" e o "operário social". Por este motivo o autor chega à conclusão de que o trabalho imaterial seria uma fábula.

Sobre a relação entre as diferentes formas de trabalho e a extração de mais-valia, Marx afirma: "não importa ao processo de criação da mais-valia que o trabalho de que se apossa o capitalista seja trabalho simples, trabalho social médio, ou trabalho mais complexo, de peso específico superior" (MARX, 2006, p. 230). Por conseguinte, as diferenças qualitativas de trabalho (seja material ou imaterial), quando abstraídas de suas dimensões concretas, isto é, excluídas as próprias diferenças qualitativas, torna-se apenas a capacidade de dispêndio de trabalho humano gerador de valor. É esse elemento oculto que interessa na produção da mais-valia.

Para caminharmos à conclusão do item e indicar o último ponto de crítica, nos remetamos à seguinte questão, já colocada, em outro contexto, por Graciolli: “a questão é saber se tais mudanças colocaram por terra o estranhamento ou o sofisticaram" (GRACIOLLI, 2007, p. 22). Em Negri, Lazzarato, Hardt e Cocco o trabalho imaterial assume uma posição de superação em relação aos condicionantes degradantes do trabalho no capitalismo. Se, a partir de Marx (2004b), o trabalho na sociedade capitalista opera em quatro níveis de estranhamento - em relação ao processo (que é exterior ao trabalhador), ao produto (que não lhe pertence), ao gênero humano (que não estabelece identidade) e ao próprio homem (por estranhar-se em relação a si mesmo) -, na vigência do trabalho imaterial todos esses elementos foram destruídos? Seguindo na análise da perspectiva teórica abordada neste item, $o$ estranhamento do trabalho, mesmo nas formas imateriais de trabalho, encontra-se conservado (Antunes, 2007). Embora o processo de trabalho imaterial assuma a aparência de o trabalhador possuir o controle do processo produtivo - e pode ser constatado empiricamente que há uma possibilidade maior de escolha - essa

aparência de maior liberdade no espaço produtivo tem como contrapartida o fato de que as personificações do trabalho devem se converter ainda mais em personificações de capital. Se assim não o fizerem, se não demonstrarem essas 'aptidões', ('vontade', 'disposição', 'desejo'), trabalhadores serão substituídos por outros que demonstrem 'perfil' e 'atributos' para aceitar esses 'novos desafios'. (ANTUNES, 2007, p. 130).

Logo, o suposto fim da relação de estranhamento no âmbito do processo laborativo imaterial pode ser contestada pelas próprias aptidões que esses trabalhadores devem possuir: isso remete ao fato de que o capitalista já cria perspectivas a priori, de modo que este já tem em mira resultados e expectativas. No grupo de autores aqui analisados, o estranhamento, portanto, se complexificaria 
mediante as formas de trabalho dos setores produtivos com índices elevadíssimos de aplicação tecnológica.

Por isso, segundo os teóricos partidários das premissas teórico-metodológicas maxianas, o trabalho imediato ainda não cessou de ser a condição de produção da riqueza.

Para concluir a presente seção, reproduziremos um trecho da contribuição de Antunes sintetiza o eixo principal da crítica que os autores marxistas proferem aos teóricos das teses recentes do trabalho imaterial, que é a subordinação desse tipo de trabalho ao processo de produção capitalista de valor:

As novas dimensões e formas de trabalho vêm trazendo um alargamento, uma ampliação e uma complexificação da atividade laborativa, de que a expansão do trabalho imaterial é exemplo. Trabalho material e imaterial, na imbricação crescente que existe entre ambos, encontram-se, entretanto, centralmente subordinados à lógica da produção de mercadorias e de capital. (ANTUNES, 2007, 128).

\section{CONCLUSÕES}

Com este artigo, não pretendemos esgotar o debate crítico sobre o trabalho imaterial. Pesquisadores de diversas matrizes teóricas têm apreendido o tema sob o ponto de vista sempre renovado. $\mathrm{O}$ presente artigo, apesar de seu caráter breve, ambiciona sugerir indicações sobre o tema.

Procuramos, no primeiro item, perpassar pelos interstícios do que aqui chamamos de recente teoria do trabalho imaterial cujos representantes principais são Antonio Negri, Michael Hardt, Maurizio Lazzarato e Giuseppe Cocco, clarificando algumas de suas teses que apontam a concepção quantitativista do emprego na análise do trabalho imaterial. Conforme vimos, esta vertente teórica analisa o trabalho imaterial como resultado da reestruturação produtiva da década de 1970. A reestruturação teve como fulcro o estabelecimento de uma nova subjetividade operária, que teria ditado os rumos do novo paradigma produtivo cujo desenho teria rompido com vários elementos do capitalismo. A mudança de uma lógica da produção para uma lógica da inovação indicaria a preponderância tendencial crescente do trabalho imaterial na produção. $\mathrm{O}$ trabalho imaterial cresceria na medida em que o trabalho material se esvaneceria.

No segundo item indicamos premissas marxianas e alguns avanços marxistas que indicam uma articulação necessária entre o trabalho material e o trabalho imaterial. Vimos que formas úteis de trabalhos que muitos autores compreendem inseridos no setor de serviços, produzem valor e maisvalia, valorizam o capital. Ao contrário dos autores do item primeiro, que possuem uma concepção unicamente positiva do trabalho imaterial, de acordo com os marxistas analisados, predomina nas relações sociais as formas de estranhamento e fetichismo típicos da sociedade capitalista. A reestruturação produtiva que impulsionou o crescimento dos postos de trabalho imateriais intensificou a produção de mercadorias enquanto unidade de valor de uso e valor. 
Na nossa compreensão o movimento do real não aponta para uma homogeneização dos processos de trabalho, ao contrário do que dizem Negri e Lazzarato, mas, indica um plano heterogêneo e complexo da esfera do trabalho. Esta é a visão, acertada em nossa opinião, de Antunes $(2005,2007)$, que alude uma imbricação crescente entre trabalho material, imaterial, produtivo, improdutivo etc., que torna a classe-que-vive-do-trabalho complexa e heterogênea.

Com o desígnio de concluir o trabalho monográfico, tendo em vista a negação vigência da teoria da mais-valia, no sistema produtivo contemporâneo, por alguns autores, pedimos permissão para tomar emprestada e modificar parte de uma expressão gramsciana que, embora tenha sido cunhada em outro contexto e dizendo respeito a outros fenômenos, a nosso ver, sintetiza os limites teóricos da recente teoria do trabalho imaterial no que diz respeito à correlação oposta entre trabalho material e imaterial: é muito fácil se deixar levar pelas diferenças exteriores entre trabalho material e imaterial e não ver as semelhanças ocultas e os nexos necessários, mas camuflados. 


\section{REFERÊNCIAS BIBLIOGRÁFICAS}

AMORIM, Henrique. Trabalho imaterial: Marx e o debate contemporâneo. São Paulo: Annablume; Fapesp, 2009.

ANTUNES, Ricardo. O caracol e sua concha: ensaios sobre a nova morfologia do trabalho. São Paulo: Boitempo, 2005.

Os sentidos do trabalho: ensaio sobre a afirmação e negação do trabalho. São Paulo: Boitempo, 2007.

COCCO, Giuseppe. Introdução. In: Trabalho imaterial: formas de vida e produção de subjetividade. Rio de Janeiro: DP\&A, 2001.

COCCO, Giuseppe; GALVÃO, Alexander; SILVA, Geraldo. Introdução: conhecimento, inovação e redes de redes. In.: Capitalismo cognitivo: trabalho, redes e inovação. Rio de Janeiro: DP\&A, 2003. p. 7-14.

CORSANI, Antonella. Elementos de uma ruptura: a hipótese do capitalismo cognitivo. In.: COCCO, G.; GALVÃ̃, A.; SILVA, G. (org.) Capitalismo cognitivo: trabalho, redes e inovação. Rio de Janeiro: DP\&A, 2003. p. 15-32.

GRACIOLLI, Edilson. Privatização da CSN: da luta de classes à parceria. São Paulo: Expressão Popular, 2007.

HARDT, M.; NEGRI, A. Império. Rio de Janeiro: Record, 2002.

2004.

O trabalho de Dionísio: para a crítica do Estado pós-moderno. Juiz de Fora: UFJF-Pazulin,

Le concept de travail immatériael; la grande entreprise. Paris: Future Antérieur, 1992. <Disponível em: http://multitudes.samizdat.net/Le-concept-de-travail-immateriel >. Data de acesso: $15 / 11 / 2009$.

. Trabalho autônomo, produção por meio de linguagem e General Intellect. In.: Trabalho imaterial: formas e vida e produção de subjetividade. Rio de Janeiro: DP\&A, 2001d.

O ciclo da produção imaterial. In.: Trabalho imaterial: formas e vida e produção de subjetividade. Rio de Janeiro: DP\&A, 2001a.

LESSA, Sérgio. Para além de Marx? : crítica da teoria do trabalho imaterial. São Paulo: Xamã, 2005.

LOJKINE, Jean. A revolução informacional. São Paulo: Cortez, 2002.

. Contribuição à crítica da economia política. São Paulo: Expressão Popular, 2008.

O capital: crítica da economia política. livro 1, v. 1. Rio de Janeiro: Civilização Brasileira, 2006.

$2008 \mathrm{a}$.

O capital: crítica da economia política. livro 1, v. 2. Rio de Janeiro: Civilização Brasileira, 
O capital: crítica da economia política. livro 2, v. 3. Rio de Janeiro: Civilização Brasileira, $2008 b$.

MARX, Karl. Capítulo VI Inédito de O Capital. São Paulo: Centauro, 2004.

. Manuscritos econômico-filosóficos. São Paulo: Boitempo, 2004b.

SANTOS, Vinícius Oliveira. Trabalho imaterial e teoria do valor em Marx: semelhanças ocultas e nexos necessários. São Paulo: Expressão Popular, 2013.

Trabalho imaterial e produção imaterial: elementos de uma análise a partir de Marx. 2018. Tese (doutorado) - Universidade Estadual de Campinas, Instituto de Filosofia e Ciências Humanas, Campinas, SP. Disponível em: http://www.repositorio.unicamp.br/handle/REPOSIP/335204. Acesso em: 3 mai. 2021.

PRADO, Eleutério. Desmedida do valor: crítica da pós-grande indústria. São Paulo: Xamã, 2005. 